\title{
TRADUZINDO OS RECURSOS SONOROS DO LIVRO I DA UTOPIA PARA O PORTUGUÊS DO BRASIL
}

\author{
Ana Cláudia Romano Ribeiro* \\ Universidade Federal de São Paulo
}

\begin{abstract}
Resumo: O texto latino da Utopia de Thomas Morus está repleto de recursos sonoro-semânticos, poucos deles levados em conta nas versões da obra para outros idiomas. Ainda que raramente observados pelos tradutores, esses recursos são importantes, afinal como observou Edward Surtz (1967), se o modo como um escritor se exprime é moldado pelas ideias, essas também são moldadas pelas ferramentas da expressão. Essa indissociabilidade foi percebida já no século XVI, como prova a atitude do humanista Juan Vives, que, em 1523, recomendava a leitura da Utopia por duas razões: pelo uso da língua e pelo assunto. E, no entanto, um dos aspectos menos trabalhados pelos críticos do libellus aureus é, justamente a especificidade da língua em que ele foi escrito, seu estilo, suas particularidades. Dentre eles, está a musicalidade, ou, nas palavras de André Prevost, os "aspectos físicos" da linguagem moreana, suas "rimas e ritmos" (cf. André Prévost, 1978). Este artigo pretende apreciar algumas "figures of sound" (a expressão é de Surtz) do livro I da Utopia. Para tanto, vamos
\end{abstract}

\footnotetext{
* Graduada em Letras (Universidade Federal de Juiz de Fora) e Etnologia (opção Etnomusicologia, Université Paris X - Nanterre), fez mestrado e doutorado pelo programa de pós-graduação em Teoria e História Literária da Universidade Estadual de Campinas, tendo realizado estágio doutoral na Università degli Studi di Firenze. É Professora Adjunta no Departamento de Letras da Escola de Filosofia, Letras e Ciências Humanas da Universidade Federal de São Paulo, na área de Língua e Literatura Francesa, e Pesquisadora Colaboradora na área de Estudos Clássicos do Instituto de Estudos da Linguagem, na Universidade Estadual de Campinas, onde desenvolve seu atual projeto de pós-doutorado que tem por objeto a Utopia de Thomas More (tradução e estudo). São Paulo, Brasil. E-mail acrribeiro@unifesp.br
} 
cotejar as passagens latinas com duas traduções brasileiras, a última tradução portuguesa e minha própria versão.

Palavras-Chave: Utopia. Thomas Morus. Recursos sonoro-semânticos. Tradução.

\title{
TRANSLATING THE FIGURES OF SOUND OF UTOPIA'S BOOK I INTO BRAZILIAN PORTUGUESE
}

\begin{abstract}
Utopia's Latin text is full of sound and meaning resources, few of them really taken into account in translations of this work to other languages. These resources are important - even if scarcely noted by translators - because, as pointed out by Edward Surtz (1967), if the manner in which a writer expresses himself is moulded by ideas, the ideas are also moulded by tools of expression. Their being indissociable was already perceived by Juan Vives in the Sixteenth century, when he gave his reasons for reading Utopia: because of both language and subject. Nevertheless, one of the least studied aspects of the libellus aureus is precisely the specificity of the language in which it was written, its style, and its particularities. Among them there is the musicality, or rather the "physical aspects" of Morean language, its "rhymes and rhythms", in the words of André Prévost (1978). This paper aims at appreciating some "figures of sound" (as said by Surtz) of Utopia's book I. For that purpose, I compare the Latin passages with two Brazilian translations, the most recent Portuguese version as well as my own.
\end{abstract}

Keywords: Utopia. Thomas Morus. Sound and meaning resources. Translation.

A Utopia foi publicada em 1516, em Lovaina, em latim, a língua franca dos meios letrados e cujo uso era caro a seu autor, Thomas Morus ${ }^{1}$. As traduções desta obra, que parecem mais atentas ao espírito do que à letra, dificilmente fazem jus ao caráter "musical" do texto latino, repleto de recursos sonoros. Essa separação entre forma e sentido, contudo, não condiz com o próprio texto da Utopia, em que, como notou Edward Surtz (e como acontece com toda grande obra literária), "The expression is molded by the ideas, and reciprocally the ideas seem influenced by the expression" (1967, p. 108). É oportuno lembrar que Juan 
Luis Vives, em 1523, recomendava a leitura da Utopia tanto pelo uso da língua quanto por seu assunto ${ }^{2}$.

De fato, um dos aspectos menos trabalhados pelos críticos da Utopia é, justamente, a especificidade do latim em que ela foi escrita, seu estilo, suas particularidades. Essa lacuna, que Surtz já havia observado em $1967^{3}$, prevalece na atualidade, conforme notou Clarence Miller em 20114. No que tange a estilo, destaco aqui, de forma bastante geral, o mesmo que Surtz, em seu artigo de 1967: "the selection and the arrangement of words and phrases" (p. 93).

Sobre o latim do libellus aureus, a bibliografia é tão curta que é possível enumerá-la brevemente. Até o momento, temos os comentários de Marie Delcourt à edição da Utopia por ela estabelecida (1936); A study of the cursus in the works of St. Thomas More (1943), de Mary Rosenda Sullivan; "Le latin de Thomas More dans Utopia" (1966), de R. Monsuez; "More's latin style in Utopia" (1966), de Edward Surtz e dois de seus artigos que integram sua edição do libellus aureus, "Utopia as a work of literary art" e "Vocabulary and diction in Utopia" (1965); "Denying the contrary: More's use of litotes in the Utopia" (1971), de Elizabeth McCutcheon; os comentários de André Prévost em sua edição da Utopia (1978); "Essai sur le vocabulaire néo-latin de Thomas More" (1998), de René Hoven; os comentários de Aires Nascimento em sua tradução para o português de Portugal (2009) e, mais recentemente, "Style and meaning in More's Utopia: Hythloday's sentences and diction" (2011), de Clarence Miller (também ele tradutor da Utopia). Além desses textos, devem ser incluídos os artigos e resenhas a respeito de traduções da Utopia que, pontualmente, comentam o uso da língua e suas traduções, e o volume organizado por Terence Cave, Thomas More's Utopia in early modern Europe. Paratexts and contexts (2012).

$\mathrm{O}$ intento deste breve artigo ${ }^{5}$ é mostrar algumas das "figures of sound" (a expressão é de Surtz (1967, p. 102) do livro I da Utopia, cotejando-as com as traduções de: 
- Luiz de Andrade (1937; que abreviei LA - cuja tradução não se sabe se foi feita direto do latim), autor da tradução da Utopia mais reproduzida no Brasil, por diversas editoras ${ }^{6}$ (mantive aqui a grafia do português desta edição);

- Camargo e Cipolla (2009; CC - que traduziram a versão inglesa de George Logan e Robert Adams, 2002); esta é a segunda tradução mais difundida da Utopia, por isso, ainda que tenha sido assumidamente feita a partir de uma das traduções inglesas, resolvi examiná-la;

- Aires Nascimento (2009; AN - que partiu do texto latino); autor da última e mais completa edição da Utopia disponível em Portugal;

- Ana Cláudia Romano Ribeiro, (RR), em andamento.

Parto do princípio de que a forma e, particularmente, os mecanismos sonoros do texto latino, estão indelevelmente associados ao que se quer dizer - para Surtz (1967, p.103-104), nascem da ideia que se quer comunicar e, ao mesmo tempo, reforçam-na. Logo, é importante tentar traduzi-los, para que não se perca este aspecto da sagacidade moreana.

As "figures of sound" de que fala Surtz são figuras de repetição ${ }^{7}$. Elas são, segundo Lausberg (2004, p. 166) "a colocação repetida, dentro do discurso, de uma parte frásica que já fora empregada". Essas figuras repetidas "detêm o fluir da informação e dão tempo para que se 'saboreie' afectivamente a informação apresentada como importante", comenta Lausberg (2004, p. 166), que as considera no âmbito da retórica desenvolvida na Antiguidade $^{8}$. No livro I da Utopia, elas estão inseridas em períodos geralmente curtos, característicos da Utopia, que, tem forma dialógica. Praticamente toda ela consiste em falas de Rafael Hitlodeu que, apenas em dois momentos, no livro I, profere sentenças extensas (de fato longas, a ponto de serem chamadas por C. Miller de "marathon sentences") 9 . Concordo com Surtz quando ele diz que "the dearth of long, complex, formal periodic sentences corresponds to the conversational and familiar nature of the discourse." (1967, p. 94) 
- característica que Morus partilha com Sêneca ${ }^{10}$, que, conforme nos foi apontado por M. C. De Pietro, diz explicitamente escrever de modo coloquial em sua Carta $75 .{ }^{11}$

Tradutores da Utopia como Marie Delcourt, André Prévost, George Logan e Clarence Miller assinalam a "linguagem variada" usada por More. Delcourt chegou até mesmo a levantar a hipótese de que se trata de um texto de caráter oral ${ }^{12}$, que teria sido ditado por More a seu secretário, John Clement ${ }^{13}$, hipótese à qual Aires Nascimento não adere, ainda que concorde que "o ritmo da frase, na sua variedade, corresponde à prática da barra de tribunal que Moro [Morus, que era advogado] utilizava com perfeição" (2009, p. 150).

Esse estilo coloquial do texto utópico e mesmo o julgamento de Morus sobre ele, em sua carta a Pieter Gillis, na qual evoca a "simplicidade negligente" (neglectam simplicitatem) (More, 1965, p. 38) de seu "livrinho" (libellum), não devem nos levar a acreditar que se trate de um texto simples. Ao contrário, conforme percebeu McCutcheon, a impressão de uma escrita natural e sem esforço é um efeito criado pelo engenho de Morus, por uma sofisticação retórica, da qual ela estudou acuradamente um aspecto, o uso das litotes, em seu artigo de $1971^{14}$. Prévost observa que estruturas sintáticas simplificadas e com modos e tempos que não seguem os usos da concordância dos tempos (consecutio temporum) do latim clássico (e parecem reproduzir a espontaneidade da língua falada) estão lado a lado com estruturas mais elaboradas formalmente " $e t$, pour répondre aux 'recherches' de sa stylistique, il va jusqu'aux limites de la préciosité et de ce que l'on appellera plus tard, en Angleterre, l'euphuisme"15 (1978, p. 243).

As figuras de som certamente contribuem para o caráter variado da linguagem na Utopia e sua presença, segundo Prévost, não surpreende "chez un auteur particulièrement sensible aux vertus de la musique" (1978, p. 249) ${ }^{16}$. Vejamos então alguns exemplos de figuras de repetição, arroladas entre as que Surtz chama de figuras de som. Dentre essas figuras de repetição, apreciarei as que se referem às repetições de partes de palavras. Não comentarei exaustivamente as opções tradutórias, limitando-me a um breve 
comentário a respeito de alguns dos jogos de sonoridades que me chamaram a atenção enquanto traduzia o livro I da Utopia.

O trecho 1 foi tirado do diálogo entre os personagens Thomas More, seu amigo Pieter Gillis e Rafael Hitlodeu, marinheiro-filósofo português. Pieter, depois de ouvir Rafael contar sobre os costumes e instituições dos diversos povos que conheceu ao percorrer o mundo, sugere que tanta experiência seria da maior valia para um rei, que se beneficiaria de seus conselhos, o que teria como consequência a melhoria das condições de vida de Hitlodeu e de seus parentes. Rafael responde que sua família não deveria esperar melhorar de vida ao preço de ele tornar-se um serviçal de reis, afinal, ele já dividira seus bens entre eles.

1 - [Hitlodeu:] [...] quos debere puto hac mea esse benignitate contentos, neque id exigere atque expectare praeterea, ut memet eorum causa regibus in seruitium dedam. [Pieter:] Bona uerba inquit Petrus, mihi uisum est non ut seruias regibus, sed inseruias. (CW 54/27-28 ${ }^{17}$ )

LA: Êles não se queixarão, espero, do meu egoismo; não exigirão que, para cumulá-los de ouro, eu me faça escravo de um rei. [...] entre estas duas palavras latinas, servire e inservire, [os príncipes] vêm apenas uma sílaba a mais, ou a menos. $(20)^{18}$

CC: Creio que isso os deixou satisfeitos, e não vão agora insistir, e muito menos exigir, que para agradá-los ainda mais eu tenha de me tornar um escravo de reis.

"Compreendo", respondeu Peter, "e concordo; mas a sugestão que fiz foi de serviços, não de servidão." (24)

AN: Julgo que eles devem ter ficado satisfeitos com a minha liberalidade e por isso não esperarão que eu, por sua causa, me ponha ao serviço de reis.

- Palavras certas, diz Pedro; a mim querer-me-ia parecer 
não que deverias servir às suas ordens, mas secundá-las. (239)

RR: [...] penso, devem estar contentes com esta minha benevolência, e não exigir mais coisas nem esperar que eu mesmo, por causa deles, seja um serviçal de reis.

- Boas palavras, disse Pieter. O que me parece, em relação aos reis, é que não seria servidão, mas serviço.

O jogo com as palavras seruitium (subst. neutro, "servidão" ${ }^{19}$ ), seruias ( $2^{\text {a }}$ pessoa do presente do subjuntivo de servio, "servir" ${ }^{20}$ ) e inseruias ( $2^{\mathrm{a}}$ pessoa do presente do subjuntivo de inservire, "servir aos interesses de" ${ }^{21}$ ) consiste numa alteração orgânica paranomástica, que põe em confronto três vocábulos com a mesma raiz, portanto semelhantes no som, cuja diferença de significado é enfatizada pela réplica de Pieter.

Em seu panorama do sistema retórico grecorromano antigo, Lausberg classifica como orgânicas as alterações fundamentadas no sistema linguístico, conectadas etimologicamente. ${ }^{22}$ Ele define a paronomásia como um

jogo de palavras respeitante à significação da palavra, o qual surge devido à alteração de uma parte do corpo da palavra, processo no qual frequentemente corresponde a uma alteração, quase imperceptível, do corpo de palavra, uma surpreendente ("que provoca estranhamento"), "paradoxal" alteração do significado da palavra (2004, p. 179).

LA optou por uma tradução explicativa, que explicita o jogo de sonoridades parecidas, transformadas nos infinitivos latinos servire e inservire - o contraste com o português recupera, em alguma medida, o estranhamento derivado da paronomásia no texto latino. O sintagma bona uerba foi suprimido, suprimindo-se assim o juízo de valor de Hitlodeu acerca das palavras de Pieter, mas uerba está 
retomada em "duas palavras latinas", que ressalta os infinitivos, chamando a atenção do leitor para o fato de serem palavras latinas.

A tradução de CC conseguiu manter, na língua de chegada, a paronomásia "serviços"/ "servidão" e criou outra, "compreendo"/“concordo" (inorgânica ou pseudo-etimológica ${ }^{23}$ ), que não está no texto latino.

Na versão de AN, o trio "serviço"/"servir"/“secundá-las" parece ser uma tentativa de traduzir, em alguma medida, a paronomásia, por meio da repetição das primeiras letras: "se-".

Em minha tradução, retomei a solução de CC, porém mantendo o singular e a ordem das palavras do texto de Morus (primeiro a negação, "não seria servidão", depois a proposição afirmativa, "mas serviço"). Também mantive a grafia original do nome Pieter, de forma a indicar sua proveniência (Antuérpia, na região de Flandres).

$\mathrm{Na}$ esteira de AN, mantive a aliteração do par uerba/uisum no par "palavras"/“parecer”.

O trecho 2 é extraído de uma fala de Hitlodeu, em que ele reproduz o diálogo travado entre ele, um advogado e o cardeal Morton. Antecede ao trecho 2 a análise, feita por Hitlodeu, dos motivos que levam pessoas a roubar, sendo o principal deles, a criação de ovelhas, que se tornam devoradoras de homens (a imagem de ovelhas que devoram homens, em $C W 64 / 31-33-66 / 1$, talvez seja a mais célebre do livro I). Proprietários de terra, não mais satisfeitos com suas rendas, transformam todas as suas terras em pasto para ovelhas, deixando de cultivar a terra e expulsando os camponeses. São eles os sujeitos dos verbos do trecho a seguir.

2 - [Hitlodeu:] [...] nihil in publicum prosint, nisi etiam obsint, [...] (66/6)

LA: [...] às expensas do público e sem proveito para o Estado [...] (29)

CC: [...] que em nada contribui para o bem da sociedade - precisam, agora, fazer-lhe positivamente o mal [...] (35) 
AN: [...] já não se incomodam com a utilidade pública, a não ser que os prejudique. [...] (248)

RR: [...] coisa alguma fazem de favorável ao bem comum, coisas desfavoráveis somente [...]

O par prosint ${ }^{24} /$ obsint $^{25}$ (dois verbos conjugados na terceira pessoa do plural do presente do subjuntivo) joga com alterações orgânicas, os prefixos pro- e ob-, responsáveis pelos sentidos opostos em um verbo formado pelo mesmo radical (sum, do verbo esse). As três primeiras traduções não mantêm a paronomásia, que, pela repetição da forma, enfatiza a antonímia.

Ainda neste trecho, deve-se notar a repetição da primeira sílaba em nihil (substantivo)/nisi (conjunção), alteração inorgânica em uma paronomásia que acentua a diferença de significado. Essa iteração está mantida nas traduções de AN ("já não"/“a não ser”) e de RR ("coisa alguma"/“coisas").

Os trechos 3 e 4 fazem parte da mesma réplica, proferida por Hitlodeu, em que está o trecho 2. Neles estão em questão aspectos financeiros das desordens econômicas advindas da criação extensiva de ovelhas: a concentração do comércio de lã nas mãos de poucos, que mantém o preço alto, independentemente do número de ovelhas.

3 - [Hitlodeu:] Quod si maxime increscat ouium numerus, precio nihil decrescit tamen (CW 68/4-5)

LA: É verdade que o número de carneiros cresce rapidamente todos os dias; mas nem por isso o preço baixou; [...] (30)

CC: Não que os preços caíssem, por mais carneiros que houvesse, $[\ldots](37)$ 
AN: Assim, mesmo quando o número de ovelhas atinge uma cifra elevada, nem por isso baixa o preço. (250)

RR: Mas, ainda que o número de carneiros acrescesse, o preço em nada decresceria.

Nesse trecho, increscat ${ }^{26}$ e decrescit ${ }^{27}$, termos compostos semelhantes na forma, além diferirem quanto ao prefixo (in-/de-), diferem também quanto ao tempo verbal (terceira pessoa do singular do presente do subjuntivo/terceira pessoa do singular do presente do indicativo). Nenhuma das três primeiras traduções mantém a tensão semântica criada nessa paronomásia pelo jogo sonoro da iteração do verbo primitivo "crescer" (cresco).

4 - [Hitlodeu:] quod earum, si monopolium appellari non potest quod non unus uendit, certe oligopolium est. ( $C W$ 68/6-7)

LA: [...] porque si (sic) o comércio das lãs não é um monopólio legal, está, na realidade, concentrado nas mãos de alguns ricos açambarcadores [...] (30)

CC: [...] pois o mercado da lã tornou-se, se não estritamente um monopólio, pois isto implicaria a existência de um só vendedor, pelo menos um oligopólio. (37)

AN: Quanto a isso, se não se pode falar em monopólio das ovelhas, já que é apenas um a vender, certamente existe um oligopólio. (250)

RR: Isso porque dos carneiros, se é impossível falar em monopólio (pois não é apenas um proprietário que vende), de oligopólio certamente é possível. 
Temos aqui dois paralelismos. Primeiramente, a correspondência sonora entre os substantivos neutros monopolium ${ }^{28} /$ oligo- $^{\circ}$ polium $^{29}$, paronomásia mantida nas traduções de CC e NA. O segundo paralelismo, formado pela litotes non potest quod non ("não pode acontecer que não") e pela repetição do verbo primitivo em potest ("pode"), que ressoa com est ("é"), foi resguardado por LA e AN. Tentei manter ambos com os pares "impossível [...] monopólio"/“oligopólio [...] possível”. Também aqui pode se dizer que o sentido é acentuado pela repetição, pelas figuras de som.

O trecho 5, assim como os trechos 2,3 e 4, também faz parte da longa fala de Hitlodeu em que ele conta o diálogo acontecido em um jantar, na casa do cardeal Morton. Tirada de uma parte chamada de intermezzo cômico (intermède comique) por Prévost, a frase abaixo envolve dois personagens do jantar, um parasita que imitava um bufão ${ }^{30} \mathrm{e}$ um frade mendicante. Ela faz parte da descrição feita por Hitlodeu desse bufão, que, ao perceber-se bem sucedido em irritar o frade, tendo-o equiparado a um vagabundo, continua a provocá-lo. Ao final, o bobo se revela sábio, e o frade, estulto. ${ }^{31}$

5 - [Hitlodeu:] Iam scurra serio scurrari coepit. (CW 82/28)

LA: Então o nosso bufão gracejou com seriedade (43)

CC: Foi então que o bobo começou a esmerar-se em suas ironias $[\ldots](51)$

AN: O bufão começou a representar a sério [...] (263)

RR: Logo o bufão começou a bufonear seriamente [...]

A reiteração pela justaposição de $s c u r r a^{32}$ (substantivo nominativo masculino)/scurrari ${ }^{33}$ (verbo no infinitivo presente) consiste num tipo de paronomásia orgânica, a figura etimológica, que pro- 
duz intensificação semântica, jogando luz no personagem e nas ações do bufão. A repetição do radical que consiste na figura etimológica "serve para a intensificação da força semântica", como em Hamlet 3,2,1 Speak the speech; vivre la vie; sein Leben leben $(2004, \text { p. } 181)^{34}$.

Nas traduções de LA, AN e RR mantém-se a oposição loucura/ seriedade (serio) que percorre toda a Utopia e costuma produzir efeitos de ironia, já que, da comparação entre países europeus e outros, não-europeus, Rafael Hitlodeu mostra ao leitor que o que uns consideram sábio pode ser loucura, e vice-versa. ${ }^{35}$ Porém, nesse excerto, a figura etimológica que enfatiza esse contraste não foi mantida nas traduções de LA, CC e AN.

O trecho 6 também está na longa fala de Hitlodeu. Refere-se à lição dos acorianos, povo situado a sudeste da Utopia, ao qual Hitlodeu atribui um aspecto exemplar, que contrasta com a política francesa da época: após ter experimentado os males advindos de uma política de expansão territorial, o rei dos acorianos decide contentar-se com o território que lhe cabe. Ao final dessa passagem, o marinheiro português aconselha ao rei francês que siga o exemplo dos acorianos, que ame os seus e seja amado por eles.

6 - [Hitlodeu:] Amet suos \& ametur a suis [...] (CW 90/18-19)

LA: [...] amai vossos súditos, e que o amor dêles faça a vossa alegria $[\ldots](49)$

CC: [...] amar seus súditos e fazer-se amar por eles [...] (60)

AN: [...] ter amor pelos seus e ser por estes retribuído [...] (271)

RR: Que ame os seus e seja amado pelos seus [...] 
Aqui temos duas alterações flexionais do corpo da palavra, ou seja, dois poliptotos ${ }^{36}$ : amet/ametur (verbo amare na terceira pessoa do presente do subjuntivo, na voz ativa/mesmo verbo, nas mesmas pessoa e modo, mas na voz passiva) e suos/a suis (pronome possessivo masculino plural no acusativo/mesmo pronome no ablativo. Procurei traduzir mantendo os poliptotos, i. e., preservando a repetição do verbo e do possessivo, cuja redundância que me parece ser propositalmente enfática. Também optei por não explicitar que o possessivo se refere a "súditos" (sentido que fica claro à luz da leitura de todo o trecho que antecede a essa passagem), para manter a ambiguidade entre suos/a suis - pronomes que, neste trecho, poderiam referir-se a familiares, mas também aos filhos, evocando assim a metáfora do rei como pai e dos súditos como filhos. Note-se, pois, que a repetição de palavras e seus sons, além de enfática, é geradora de sentidos importantes à Utopia.

CC mantém a repetição do verbo amare e a alternância da forma ativa e passiva, mas explicita o referente do possessivo e não o repete. A opção pela não repetição (uariatio) parece caracterizar, em geral, as opções tradutórias dos três primeiros tradutores nos exemplos vistos até o momento.

Antes do próximo excerto, Hitlodeu imagina conselheiros reunidos para encontrarem modos de aumentar a riqueza de um rei. A primeira estratégia é apresentada no trecho 7.

7 - [Hitlodeu:] [...] dum unus intendendam consulit aestimationem monetae, quum ipsi sit eroganda pecunia. deijciendam rursus infra iustum, quum fuerit corroganda. ( $C W$ 90/25-27)

LA: Êste propõe elevar o valor da moeda quando se trate de reembolsar um empréstimo, e de fazê-lo descer muito abaixo do par quando se trate de tornar a encher o tesouro. (49) 
CC: Um deles sugere que se aumente o valor da moeda sempre que o rei tiver de fazer algum pagamento e se reduza esse valor sempre que tiver dinheiro a receber. (60)

AN: Um conselheiro sustenta que se faça a apreciação da moeda, no momento em que o rei vai lançar uma nova, para de seguida a fazer baixar além do valor real logo que precisar recolher. (271-272)

RR: Enquanto um decide pelo aumento do valor da moeda quando se deva desembolsar em dinheiro e em seguida, pela diminuição abaixo do valor real quando se for embolsar [...]

Novamente, nas três primeiras traduções, a paronomásia que une os particípios no nominativo feminino singular eroganda ${ }^{37}$ / corrogand $^{38}$ não foi traduzida. LA e CC mantiveram o paralelismo ("se trate de reembolsar/se trate de tornar a encher" e "tiver de fazer algum pagamento/ tiver dinheiro a receber"). Em minha tradução, tentei manter a alteração orgânica no par "desembolsar"/“embolsar".

O trecho abaixo é a conclusão de uma parte da fala de Hitlodeu em que ele pondera que a impossibilidade de erradicar de vez todos os erros da política não deve ser motivo para voltar as costas à vida pública, assim como um navio não deve ser abandonado porque não se consegue deter os ventos.

8 - [Hitlodeu:] Nam ut omnia bene sint, fieri non potest, nisi omnes boni sint [...] (CW 100/2-3)

LA: [...] porque tudo só será bom e perfeito, quando os próprios homens forem bons e perfeitos [...] (56) 
CC: Pois as coisas jamais serão perfeitas enquanto os homens não atingirem a perfeição. (69)

AN: De facto, não é possível que tudo dê em bem senão quando todos forem bons [...] (279)

RR: Pois não será possível estar tudo bem a não ser que sejam todos bons [...]

Temos aqui dois poliptotos: omnia ${ }^{39} /$ omnes $^{40}$ (substantivos no nominativo e no plural, o primeiro neutro, o segundo, masculino) e bene/boni (advérbio/adjetivo no nominativo plural masculino). $\mathrm{O}$ ritmo regular deste trecho também é reforçado pela aliteração em nam/nisi e pela repetição do verbo.

A tradução de LA faz uma amplificatio ("bom e perfeito" no lugar de bene) nos moldes da primeira tradução para o inglês da Utopia (Ralph Robynson, 1551), enquanto a de CC interpreta bene/boni como "perfeitas"/“perfeição", o que aproxima a Utopia do pensamento platônico, algo sugerido pelo próprio Morus em várias passagens de seu livro. Os poliptotos deste trecho são particularmente difíceis de se manter na tradução: apenas LA conseguiu manter o mesmo verbo, ao preço de traduzir o advérbio bene pelos adjetivos "bom e perfeito". Optei por traduzir omnia por "tudo" (ao invés de "todas as coisas", minha opção anterior), que tem o mesmo número de sílabas que "todos", assim como no par omnial omnes. Traduzir bene por um advérbio me obrigou a variar sint/ sint, traduzindo a primeira ocorrência por "estar". Também alterei a ordem das palavras, buscando manter um ritmo (mutatis mutandis) semelhante ao do original. Continuo tentando encontrar uma solução mais fiel à forma e ao som.

$\mathrm{Na}$ tradução de AN, a aliteração em nam/nisi encontra um correspondente em não/senão. Seu fraseado também me parece ser o mais próximo do original, entre os quatro. 
O trecho 9 faz parte de uma passagem final do livro I em que Hitlodeu descreve a Utopia, onde, com poucas leis, todas as coisas são exemplarmente administradas, e a compara com outros países, onde tantas leis são feitas, sem que isso garanta uma vida melhor.

9 - [Hitlodeu:] [...] tot nationes alias, semper ordinantes, nec ullam satis ordinatam unquam [...] (CW 102/31-32)

LA: [Nas passagens que antecedem e vêm depois deste trecho, há grandes diferenças entre o texto latino e o texto em português. A tradução que está no lugar do trecho acima é esta: "A prova é o número infinito de processos que surgem todos os dias e não terminam nunca." (59)]

CC: [...] tantos países que fazem leis sem cessar, e não obstante são sempre incapazes de solucionar seus problemas. (73)

AN: [...] nações, onde incessantemente se fazem leis, sem que nenhuma delas seja alguma vez suficientemente perfeita $[\ldots](282)$

RR: [...] várias nações estrangeiras, sempre fazendo ordenanças, nenhuma nunca ordenada o suficiente [...]

O poliptoto ordinantes (nom. pl. fem.)/ordinatam (ac. sg. fem.) é formado pelos por duas formas participiais do verbo ordinare ("ordenar") $)^{41}$, que, no contexto, se refere a ordenar o que se refere a um país, inclusive no aspecto legal. Em minha versão, tentei manter a figura de repetição, transformando o particípio ordinantes em "fazendo ordenanças" e ordinatam, em "ordenada". 
AN criou uma paronomásia com o par "incessantemente"/“suf icientemente”, mas, como LA e CC, não traduziu o jogo ordinantes/ordinatam.

Os exemplos mostram que, no texto latino, as figuras de repetição, ou figuras de som, se constroem utilizando-se termos da mesma família (scurra/ scurrari; bene/boni), palavras derivadas por prefixação (seruias/inseruias; prosint/obsint; increscat/decrescit; monopolium/oligopolium; potest/est; eroganda/corroganda), palavras com diferenças flexionais (amet/ametur; suos/a suis; omnial omnes; ordinantes/ordinatam) ou mesmo reiteração consecutiva de vocábulos (sint/sint). Tais procedimentos parecem querer chamar a atenção do leitor tanto para o que é dito quanto para o modo como é dito, indicando que uma tensão semântica acompanha essas figuras de repetição. Das nove que listei, oito estão nas réplicas de Hitlodeu, que ocupam a maior parte do livro I. Traduzir essas e outras figuras é nosso escopo, seguindo o pressuposto de que a forma significa: "The devices of sound, judiciously employed, spring from idea and feeling and, at the same time, reinforce both - as they should", como afirma Surtz (1967, p. 104). É ao modo como a forma significa na narrativa e na argumentação da Utopia de Morus que pretendo me dedicar na continuação deste trabalho.

\section{Notas}

1. "Dans la controverse avec Luther et Tyndale de 1523 à 1533 , il [Morus] se fera - en anglais! - l'avocat du latin universel, symbole de l'unité de la culture et de la fidélité à la tradition.” (PRÉVOST, 1978, p. 242)

2. Essa informação é reportada por Surtz: “Already in October 1523, in response to Catherine of Aragon's request for a program of study for Princess Mary, Vives was recommending the Utopia for both style and content: 'Auctores in qui- 
bus versabitur, ii erunt qui pariter et linguam et mores excolant, atque instituant; quique non modo bene scire doceant, sed bene vivere; hujusmodi sunt Cicero, Seneca, Plutarchi opera..., aliquot Platonis opera, praesertim qui ad rempublicam gubernandam spectant, ... Erasmi institutio principis, ... Thomas Mori Utopia'" (apud SURTZ, 1967, p. 109, n. 8).

3. Surtz, após ter escrito sobre o estilo na Utopia em dois textos publicados juntamente à sua edição do libellus aureus (em MORE, 1965), escreveu um artigo em que analisa, à luz do De copia, de Erasmo, os recursos estilísticos empregados por More em sua obra mais conhecida. Ao final deste artigo, ele reconhece a necessidade de continuidade das pesquisas nesse campo: "The present analysis, in a sense, has merely scratched the surface. Detailed and painstaiking studies need to be made of every element of style, perhaps in verification, perhaps in rebuttal, of the assertions made and conclusions reached in this article and in the recent edition of the Utopia" (1967, p. 107, n. 7).

4. Segundo Miller, "very few studies pay much attention to the actual continuous language, the style(s) of the work" (2011, p. 71).

5. Este artigo beneficiou-se da leitura de Isabella T. Cardoso e Matheus Clemente De Pietro, aos quais agradeço.

6. Como, por exemplo, a editora Abril, em sua coleção Os Pensadores. Para um panorama das edições brasileiras da Utopia, ver Ribeiro, 2012.

7. Sobre os efeitos da repetição, Lausberg coloca: "Serve assim à amplificatio afetiva. Neste caso é de distinguir a igualdade completa da igualdade branda [será este o caso da paronomásia]. $\mathrm{O}$ abrandamento da igualdade é um fenómeno de transição para a acumulação" (2004, 241, p. 166, grifo meu).

8. Sobre a repetição como recurso poético em Roma antiga (em especial no período augústeo), cf. Wills, 1996.

9. Sobre esses períodos, ver Surtz (1967) e, sobre seu significado, ver Miller (2011).

10. Sêneca, ao lado de Cícero, são tidos em alta conta por Rafael Hitlodeu. Cf. More, $C W$ 48/31-33-50/1-3. 
11. "Você reclama que lhe são enviadas por mim cartas menos caprichadas. Mas quem fala com capricho, senão quem quer falar de modo afetado? Caso estivéssemos sentados ou andando juntos, o meu discurso seria simples e acessível; assim eu quero que minhas cartas sejam: que elas nada tenham de supérfluo ou de artificial." (Sêneca, Ep. 75.1) Sobre o estilo de Sêneca e o uso extensivo de períodos curtos, cf. Quintiliano, I.O., 10, 130, minutissimis sententiis; Braren, 1999; Von Albrecht, 2008, p. 71). Sobre este e outros aspectos da relação entre estilo ee a argumentação de Sêneca, ver De Pietro, 2008 e 2013, e Oliveira, 2014.

12. "Ses phrases plaines d'éllipses, coupées de paranthèses, donnent l'impression de la langue parlée" (DELCOURT, 1936, p. 28).

13. André Prévost nota as imprecisões da pontuação, as ligações entre as frases desprovidas de originalidade e os trechos entre parênteses, que seriam, para ele, um recurso de Morus para dar à Utopia "l'allure du style oral". Ele continua: "Il semble bien que certaines pages aient été dictées au sécrétaire John Clement et que le style n'en aurait pas été châtié par la suite" (1978, p. 245).

14. Este artigo foi republicado em Essential articles for the study of Thomas More, de 1977.

15. O euphuisme, ou linguagem preciosa, foi colocado em prática em Euphues (1578), de John Lyly.

16. Prévost evoca a importância dada à música na descrição da comunidade utópica, cf. p. 92 e 155 de sua edição da Utopia: "Nulla coena sine musica transigitur. nec ullis caret secunda mensa bellarijs. odores incendunt, \& unguenta spargunt. nihilque non faciunt, quod exhilarare conuiuas possit. sunt enim hanc in partem aliquanto procliuiores, ut nullum uoluptatis genus (ex quo nihil sequatur incommodi) censeat interdictum." (CW 144/16-23); "[...] sicuti quae nobis in usu sunt, multum suauitate uincunt. ita quaedam nostris ne conferenda quidem sint. Verum una in re haud dubie longo nos interuallo praecellunt, quod omnis eorum musica, siue quae personatur organis, siue quam uoce modulantur humana, ita naturales affectus imitatur \& exprimit, ita sonus acommodatur ad rem, seu deprecantis oratio sit, seu laeta, placabilis turbida, lugubris, irata, ita rei sensum quendam melodiae forma repraesentat, ut animos auditorum mirum in modum afficiat, penetret, incendat" (CW 236/1-9).

17. Essa referência se refere à edição da Utopia publicada nas obras completas (Complete Works) de Thomas Morus, seguida dos números de página e das linhas. 
18. O número entre parênteses, que segue os trechos traduzidos, refere-se à página das traduções acima citadas.

19. Cf. verbete servitium no $O L D:: 1$ The condition of being a slave or servant, slavery, bondage.

20. Cf. verbete servio no $O L D: 1$ To serve (a master) in the capacity of slave, wait on, to be servant of; 2 To be politically subject; 3 To put one's self at the service of, labour for; 4 To act in subservience, subordinate one's actions; 5 To be at the service of, be employed (for), to serve (for), to duty (as).

21. Cf. verbete inservio no $O L D:: 1$ To serve the interests of; devote or attach oneself to.

22. A paronomásia se funda, segundo Lausberg, sobre uma alteração orgânica do corpo de palavra, e "por meio de fenómenos que criam palavras" (como os prefixos e sufixos), produz "um significado alterado de palavra, ainda que este significado the seja aparentado" (LAUSBERG, 2004, p. 180). Ela pode reforçar: - a diferença de significado (Rhet. Her. 4,21,19 hic sibi posset temperare, si amori mallet obtemperare; Lus. VIII, 24, 8 Que a coroa de palma ali coroa) ou; - o parentesco de significado (Androm. 4,5,1312 vous vous abandonniez au crime em criminel; Ter. Heaut. 77 homo sum, humani nil a me alienum puto).

A paronomásia implica efeitos de som: "G.J. Vossius verweist auf das lateinische Wort annominatio (gr. ఐароvо $\mu$ aбia, paronomasia), das er dem Sinn nach mit der Aliteration gleichsetzt: «annominatio [...] recentiores alliterationem vocant» (Die Modernen bezeichnen die A. als annominatio). ("G. S. Vossius refere-se à palavra latina annominatio (gr. ఐapovo $\mu \alpha \sigma i ́ a$, paronomasia), à qual ele atribui o mesmo significado de Aliteração: "annominatio [...] recentiores alliterationem uocant" (os modernos entendem a aliteração como annominatio"). (Verbete "Alliteration", in $H W R$, traduzido por Julia C. Brandão)

23. As alterações "inorgânicas" esbarram contra o sistema linguístico (na expressão de Lausberg), causando estranhamento, e, também essas, configuram-se como paronomásia. Entre as palavra que constituem esse tipo de paronomásia cria-se uma "ligação (pseudo-)etimológica, na medida em que, entre os dois corpos de palavra e suas significações, é constatado um parentesco, ao mesmo tempo que uma diferença." (LAUSBERG, 2004, p. 179) Segundo ele, a alteração inorgânica pode reforçar: - a diferença de significado (Cic. Att. 1,13,2 facie magis quam facetiis/ ridiculus; RJ 3,3,41 This may flies do, when from this must fly; 3,4,8 
These times of woe afford no time to woo) ou; - o parentesco de significado (Cic. Att. 1,13,2 parvo animo et pravo; Vieira IX, 466 mas não tremas, nem temas).

24. Cf. verbete obsum: To be a hindrance, nuisance, or disadvantage (to), to be prejudicial to the interests of, do harm. $(O L D)$

25. Cf. verbete prosum: 2 (of concr. or abstr. things) To be helpful, advantageous, beneficial, etc. $(O L D)$

26. Cf. verbete incresco: 1 To develop, grow. [...] c To increase in numer or amount. $(O L D)$

27. Cf. verbete decresco: 1 To grow smaller in size, dwindle, shrink (OLD)

28. Cf. verbete monopolium: The right of exclusive sale of a commodity, monopoly. $(O L D)$

29. Cf. verbete oligopolium: Nem o Thesaurus Linguae Latinae, OLD, nem o Gaffiot registram essa palavra que, em português (oligopólio) indica; "Situação de mercado na qual, num limitado número de produtores, cada um é bastante forte para influenciar o mercado, mas não o é para desprezar a reação dos competidores. (Aurélio)

30. Adstabat forte parasitus quidam, qui uideri uolebat imitari morionem, sed ita simulabat, ut propior nero esset, tam frigidis dictis captans risum, ut ipse saepius, quam dicta sua rideretur. ("Aconteceu de estar ali presente certo parasita, que queria imitar um bobo, mas imitava de tal modo que se aproximava cada vez mais de ser um de verdade. Seus ditos requentados faziam rir, sendo ele mesmo mais risível do que seus ditos." RR)

31. A tópica da inversão de valores está presente tanto na Utopia quanto no Elogio da loucura, de Erasmo, e é desenvolvida em diferentes momentos e em vários níveis. Sobre isso, ver, por exemplo, Marc'Hadour, 1971.

32. Cf. verbete scurra: A fashionable city idler, 'man about town'; (the term came to be used mainly w. ref. to the offensive wit affected by such a person, and from Augustan times denoted a professional buffoon, or sim). (OLD) 
33. Cf. verbete scurror: To play the scurra, i.e. dine off one's jokes. $(O L D)$

34. Segundo Lausberg, a repetição do radical é "chamada, nos tempos modernos, figura etymologica e considerada, na antiguidade, como pertencente à derivatio

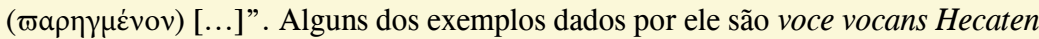
(Aen. 6, 247), ire iter (Georg. 4, 108). A edição portuguesa acrescenta exemplos, dentre eles Tristezas que não cansam de cansar-me (Camões, Sonetos, 67, 2) e viver uma vida divina (Vieira, IX, 129) (2004, p. 181).

35. Sobre ironia, sátira e ambiguidade na Utopia ver, por exemplo, Heiserman (1963) e McCutcheon (1971).

36. O poliptoto, assim como a paronomásia e a figura etimológica, também é um tipo de alteração orgânica. Ele "consiste na alteração flexional do corpo da palavra", não provocando alteração no significado, "mas tão-só uma alteração da perspectiva sintáctica" (LAUSBERG, 2004, p. 180, que dá varios exemplos, entre eles $O d .1,3$ шо $\left.\lambda \lambda \tilde{\omega} v \ldots . . / \pi \mathrm{o} \lambda \lambda \alpha_{\alpha} . ..\right)$.

37. Cf. verbete erogo: To pay out, disburse, expend (public money, orig. after passing a rogatio). (OLD)

38. Cf. verbete corrogo: To collect (money, etc.) by begging or entreaty. (OLD)

39. Cf. verbete omnis: 3 (neut. pl. as sb) The whole amount, situation, affair, place, etc., everything. $(O L D)$

40. Cf. verbete omnis: $2 \mathrm{~b}$ (masc. as sb) the whole body of persons concerned. $(O L D)$

41. Cf. verbete ordino: 3 To make orderly or systematic, organize, etc.; (esp.) to settle the affairs of (a country or people); 4 a To put together (a document, etc.) in proper form, draw up, compose. $\mathrm{b}$ to institute (legal proceedings) in due form. c to carry out (a procedure) in due order. $(O L D)$ 


\section{Referências}

BRAREN, Ingeborg. "Por que Sêneca escreveu epístolas?”. Letras clássicas, 3, 1999, p. 39-44.

CAVE, Terence (Ed.). Thomas More's Utopia in early modern Europe. Paratexts and contexts. For the project "Dislocation: practices of cultural transfer in the early modern period" at the University of Oslo. Manchester/New York: Manchester University Press, 2012.

DE PIETRO, Matheus Clemente. Faces da "harmonia" nas Epistulas morales de Sêneca. Dissertação (Mestrado). Campinas: Universidade Estadual de Campinas, 2008.

. Noções estoicas de harmonia no De vita beata de Sêneca. Tese (Doutorado) Campinas: Universidade Estadual de Campinas, 2013.

HOVEN, René. Essai sur le vocabulaire néo-latin de Thomas More. In: Lexique de la prose latine de la renaissance. Dictionary of Renaissance Latin from prose sources. Deuxième édition revue et considérablement augmentée/Second, revised, and significantly expanded edition. Avec la collaboration de/Assisted by Laurent Grailet. Traduction anglaise par/ English translation by Cohen Maas. Revue par/ Revised by Karin Renard-Jadoul. Leiden-Boston: Brill, 2006, p. 659-683.

LAUSBERG, Heinrich. Elementos de retórica literária. Tradução, prefácio e aditamentos de R. M. Rosado Fernandes. $5^{\text {a }}$ ed. Lisboa: Fundação Calouste Gulbenkian, 2004.

MARC'HADOUR, G. Thomas More ou la sage folie. Paris: Seghers, 1971.

McCUTCHEON, Elizabeth. Denying the contrary: More's use of litotes in the Utopia. Moreana, 31-32, 1971, p. 107-122.

MILLER, Clarence. Style and meaning in More's Utopia: Hythloday's sentences and diction. In: Humanism and style. Essays on Erasmus and More. With na Introduction by Jerry Harp. Bethlehem: Lehigh University Press, 2011. 
MONSUEZ, R. Le Latin de Thomas More dans Utopia, Annales publiées par la Faculté des Lettres et Sciences Humaines de Toulouse, Nouvelle Série, t. II, fasc. I, janvier, 1966, Caliban, 3, p. 35-78.

MOORE [sic], Thomas. A Utopia. Tradução e prefácio de Luiz de Andrade. Rio de Janeiro: Athena, 1937.

MORE, Thomas. MORE, Thomas. Utopia. In: Surtz, Edward S.J.; Hexter, J.H. (ed.). The Complete Works of St. Thomas More, vol. 4. New Haven and London: Yale University Press, 1965.

. L'Utopie. Présentation, texte original, apparat critique, exegèse, traduction et notes de André Prévost. Paris: Mame, 1978.

. Utopia. Edited by George M. Logan and Robert M. Adams. Revised edition. [ $1^{\text {a }}$ ed. 1989] Cambridge: Cambridge University Press, 2002.

. Utopia. [ $1^{\mathrm{a}}$ ed. 1993] George M. Logan e Robert M. Adams (orgs). Edição revista e ampliada. Tradução Jefferson L. Camargo e Marcelo B. Cipolla. São Paulo: Martins Fontes, 2009.

MORVS, Thomas. Vtopia ou A melhor forma de governo. Tradução, com prefácio e notas de comentário de Aires A. Nascimento. Estudo introdutório de José V. de Pina Martins. Lisboa: Fundação Calouste Gulbenkian, 2009.

PRÉVOST, André. Le texte de l'Utopie (Les premières éditions de l'Utopie; La langue latine de l'Utopie; Les traductions de l'Utopie; Directives pour la lecture du fac-similé). In: More, Thomas. L'Utopie. Présentation, texte original, apparat critique, exegèse, traduction et notes de André Prévost. Paris: Mame, 1978, p. 215-275.

RIBEIRO, A. C. R. As traduções brasileiras de $A$ Utopia, de Tomás Morus. In: Anais do II Encontro Tricordiano de Linguística e Literatura, Memento, 2012, 3. p. 4-12.

SURTZ, Edward L. Utopia as a work of literary art; Vocabulary and diction in Utopia. In: More, Thomas. Utopia. In: SURTZ, Edward S.J.; HEXTER, J.H. 
(ed.). The Complete Works of St. Thomas More, vol. 4. New Haven and London: Yale University Press, 1965, p. cxxv-cliii; 579-582. 1967, p. 93-109.

. Aspects of More's latin style in Utopia. Studies in the Renaissance, 14,

VON ALBRECHT, M. Seneca's Language and Style I. Hyperboreous, v. 14, 2008.

WILLS, J. Repetition in latin poetry: figures of allusion. Oxford: Clarendon Press, 1996.

Recebido em: 23/06/2015 Aceito em: 15/08/2015 